\title{
Elevating Students acquaintance through a Value Added Course by Transforming Conceptual ideas to Pragmatic approach using an online platform
}

\author{
Anupama R Itagi, Jayashree Mallidu,Padmaja Kallimani \\ Department of Electrical and Electronics Engineering, KLE Technological University, \\ Hubballi, Karnataka, India. \\ Email: anupama_itagi@kletech.ac.in,jayashree.mallidu@kletech.ac.in,padmaja.kallimani@kletech.ac.in
}

\begin{abstract}
- the success rate in the career of an individual depends mainly on the knowledge acquired during graduation. In the current COVID -19 pandemic scenario, engaging students to develop practical skills through an online platform is inevitable. Students by the end of graduation need to be industry-ready, for which working in a team to refine practical skills is mandatory. It is a known fact that due to cognitive diversity, working in a team makes it possible to perceive different perspectives, supplement one another, and make a reciprocal contribution towards the achievement of goals. Applying conceptual ideas in a team to en- hance the hands-on experience is one of the tactics. Hence, in this paper, the authors propose the inclusion of Value Added Course (VAC) in the Electrical and Electronics Engineering curriculum to make students proficient and industry-ready. VAC can be offered to students during vacation, soon after the completion of thirdsemester exams. The use of an appropriate online platform addresses the requirements of the Teaching-Learning process. This paper proposes supplementing the initial steps of product design to assimilate fore knowledge of fundamental courses of third semester through pragmatic approach. The effectiveness of the proposed methodology is described by measuring the Graduate Attributes attained.
\end{abstract}

Index Terms - online teaching, Value Added Course, assimilation of fundamental courses, pragmatic approach.

\section{INTRODUCTION}

For an engineering student to succeed in his career, superior knowledge of theoretical and practical knowledge is mandatory. Due to the vulnerable situation created by the COVID19 pandemic, it is not advisable for students to attend regular classes. However, making students industry ready is still the responsibility of the course instructor. Hence careful selection and design of teaching-learning methodology are among the significant challenges posed by COVID-19 pandemic to the course instructors.

Accustomed delivery of fundamental courses of third semester like Analog Electronics Circuits (AEC), Digital Electronics Circuits (DEC), and 8051 microcontroller included classroom teaching and implementing certain concepts in the laboratory. The relevance of these courses in various applications is not demonstrated in the conventional method of teaching. This gap can be bridged by incorporating VAC in the Curriculum. Since the COVID-19 scenario is predicted to continue for at least another six months, it necessitates course instructors to deliver vital knowledge of VAC through various online platforms like Microsoft Teams, ZOOM, CiscoWebex, etc to make students industry-ready. In this paper, the authors propose delivery of VAC to transform conceptual ideas to pragmatic approach.

The paper is organized as follows. Section II discusses the benefits and challenges of VAC using the online-pedagogy method. Section III focuses on the proposed methodology. Section IV presents problem statement formation criteria. Section V presents an example for VAC. Section VI emphasis on road map for quality upgrading of proposed method. Section VII discusses the evaluation and attainment of the proposed pedagogical method. Section VIII discusses possible attainment of graduate attributes and section IX concludes the paper.

\section{VAlue Added Course}

Value Added Course is the technical training that students undergo to gain additional skills with the main objective of employability competence. Such course can be introduced in the curriculum with incentives such as extra credits and certification and hence enable active participation of students in Engineering studies [2]. Due to pandemic situation, the course can be carried out through online platforms.

\section{A. Benefits}

The benefits of VAC are as follows

- It is an aid for students to assimilate learning of various fundamental courses.

- Help students to develop inter-disciplinary skills.

- Early exposure to an organized approach of carrying out project work.

- Help students to take up projects of a higher level so that individual performance can be upgraded.

- It is a boon to make students industry-ready.

- Teamwork is encouraged.

- Students can learn to manage the work online.

- It offers an opportunity to explore various software tools. 
- Availability of recorded videos helping students to learn comfortably in their own pace.

- Helps the student to become entrepreneurial [1].

- Caters to the needs of students of all learning styles [2].

B. Challenges

The challenges of VAC are as follows

- Challenging for the teacher to judge the level of involvement of the student in learning.

- Network issues in rural areas.

- Online mode of content delivery is much prone to weather conditions.

\section{Proposed Methodology}

"Tell me and I forget, teach me and I may remember, involve me and I learn." - Benjamin Franklin

As quoted above, it is observed that involving students in different ways enhances the learning.

In traditional curriculum of Engineering, students get less opportunity to transform theoretical knowledge to practical, as students are offered one or two projects from third year onwards. Student's performance in third year of project work may deteriorate due to lack of exposure to transform conceptual learning to experiential learning. However the projects that students take up during pre final year play an important role in boosting technical knowledge and confidence. Hence, to create experiential learning environment in the early days of engineering, authors propose inclusion of VAC in the second year of Engineering curriculum. In the mid of third semester, students have to be briefed regarding overview and benefits of VAC. Interested students can enroll for the course during vacation. The authors propose VAC implementation in a team of 4 students. A team is a combination of individuals who possesses different knowledge and skills. The Team formation can be based on student Cumulative Grade Point Average (CGPA)/ combination of a lateral entry and non-lateral entry students/ atleast one female candidate in a team. Ideally, the faculties involved in delivery of AEC, DEC, and 8051 microcontroller courses can play mentors' role. Thus students can be educated regarding different steps involved in an execution of projects.

To accommodate experiential learning at an early stage of Engineering, course instructors have to play a crucial role in designing course structure, problem statements, and delivery mode. In this paper, authors propose problem statement combining various fundamental courses. The proposed course aims to make student implement the given problem statement by applying foreknowledge and there by upgrading their skills. Thus, the proposed methodology aids student to comprehend a few design concepts and use various software tools to achieve the given task.

\section{A. Course Learning Outcomes}

At the end of VAC, student should be able to

- Assimilate learning of various fundamental courses of third semester.

- Use software tools to verify working of various circuits.
- Comprehend and use desired content of the data sheet.

- Acquire minimum fundamental design concepts.

- Upgrade knowledge/skills meeting industry requirements.

- Comprehend standard procedure of documentation.

\section{Problem Statement Formation Criteria} lows

The criteria for problem statement formulation are as fol-

- Comprise of fundamental courses offered during third semester of engineering.

- Student should be able to apply learning of fundamental courses.

- There should be scope to understand and use desired content of data sheet.

- Problem statement should aid in applying fundamental concepts to explain, interpret, and predict the system's behavior.

- There should be scope for upgrading knowledge/ skills meeting industry requirements.

- There should be an opportunity for student to acquire fundamental design concepts.

\section{ILlustrative EXAMPLE}

This section presents a sample example that can be a part of VAC with students. The problem statement discussed here basically assimilates fundamental courses like DEC and microcontroller/ AEC courses.

A student is assigned the task to design and implement a smaller block of his project work. He has to implement a digital clock calendar. He has all the required components to execute the task except the signal generator. Hence to trigger the digital circuit, a pulse signal is to be generated. Due to the pandemic situation, the person is accessible to other few resources like 8051 microcontroller kit with USB programmer/basic microcontroller, 555 timer, DAC, ADC, and passive components. Propose a solution to the task of generating the desired signal to implement a digital clock.

\section{ROAD MAP FOR QUALITY UPGRADING OF THE PROPOSED METHOD}

According to the authors, the suitable amalgamation of the following aspects can help upgrade VAC's quality. This also aids in making students industry-ready.

- Specify the task that is achievable in more than one way.

- Place a constraint on using the number of equipment/ specify the list of components prudently among which students have to select appropriate ones to meet the desired goal.

- Application based problem statement.

- Promote multidisciplinary work.

- Software based projects to carry out different types of analysis of complex systems.

- Formulation of Scenario based problem statements so that student can understand the different blocks and means for implementation.

- Design based problems.

- Public health and safety based problems. 


\section{EVAluation AND ATtAinment of THE PRoposed PEDAGOgicAl METHOD}

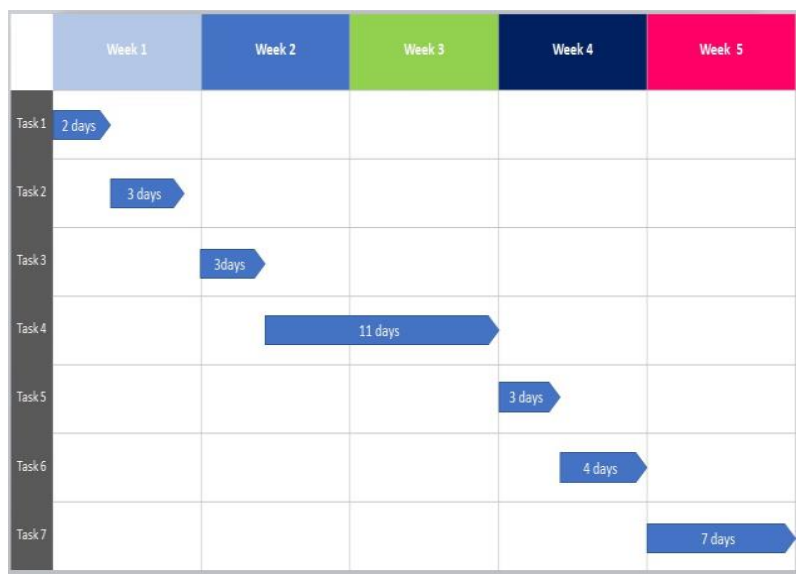

Fig. 1. Sample Gantt chart showing timeline to carryout VAC

Expected work progress per week is shared with students well in advance. It is shared through Gantt chart shown in Fig.1. Week wise task details are provided in Table 1 . Weekly progress reports need to be uploaded by students in the scheduled time. This helps course instructor to judge the level of involvement of the student in learning. After the report review, mentors have to list the necessary changes if

\section{Possible Attainment of GRAduAte ATTRIBUTES}

Description of Graduate Attributes are shown in Table III and the feasible attainment of Graduate attributes are given in Table IV [4]

\section{CONCLUSion}

This paper presents the advantages of online delivery of Value Added Course soon after the completion of third- semester exams of engineering. This intented any for each team. This helps mentor to identify and rectify the weak areas of understanding. Interaction of mentor with students on weekly basis is insisted to explain the essential changes. This can be done using various online platforms like ZOOM, MS Teams, Cisco Webex, Google Meet, etc.The frame work and marks distribution for the proposed method is given in Table II.

method can be adopted even in pathetic situation created due to COVID-

19 pandemic.Authors propose a methodology of carrying out course project delivery assimilating the knowledge of funda- mental courses, various software tools and PCB design aspects. Value Added Course reinforces team work and enhances self- learning. The learning experience gained through this course boost students confidence in carrying out projects further in their curriculum. Authors discuss possible Graduate attributes that can be attained in the proposed method. 


\section{ACKnowledgement}

The authors would like to express their gratitude to Dr. Ashok Shetter, Vice-Chancellor, KLE Technological Univer- sity Hubballi for his continuous encouragement. Authors would also like to thank Dr A. B. Raju, H O D, department of Electrical and Electronics Engineering for his support.

\section{REFERENCES}

[1] Phillip A. Sanger Julia Ziyatdinova ““”Project based learning: Real world experiential projects creating the 21 st century engineer",'2014
International Conference on Interactive Collaborative Learning (ICL) [2] Aditya Panwar, Aniruddha Chauhan, Kavi Arya

““'Analyzing Learning

Outcomes for a Massive Online Competition through a ProjectBased Learning Engagement",'IEEE Global Engineering Education Confer- ence (EDUCON), 2020

[3] Anupama R Itagi, Sushma V, Sachin Angadi, A B Raju and Ashok Shet- tar ““'Analyzing Learning Outcomes for a Massive Online Competition through a Project-Based Learning Engagement",'Journal of Engineering Education Transformations, February 2015

[4] Anupama R Itagi, Sushma V ““"Enhanced Teaching/Learning Process in Analog Electronic Circuits with an Aid of Computer Simulation Tool",'IEEE 4th International Conference on MOOCs, Innovation and Technology in Education (MITE) 2016.

TABLE I

WEEK WISE TASK

DETAILS

\begin{tabular}{|c|l|}
\hline Task details & Task No. \\
\hline $\begin{array}{c}\text { Recapitalization of essential concepts of } \\
\text { AEC, DEC and 8051 microcontroller and } \\
\text { assigning problem statement }\end{array}$ & 1 \\
\hline $\begin{array}{c}\text { Introducing desired software tools like } \\
\text { Proteus, PCB Express and Team formation }\end{array}$ & 2 \\
\hline $\begin{array}{c}\text { Identification of sub-blocks for } \\
\text { the given problem statement, } \\
\text { Exploring desired data sheet details }\end{array}$ & 3 \\
\hline $\begin{array}{c}\text { Simulation of each sub-block } \\
\text { and integration of these blocks. }\end{array}$ & 4 \\
\hline Circuit implementation on bread board & 5 \\
\hline $\begin{array}{c}\text { Generate PCB layout using } \\
\text { appropriate software for the } \\
\text { final system to get Gerber file }\end{array}$ & 6 \\
\hline Assembling of circuit elements on PCB & 7 \\
\hline
\end{tabular}

TABLE II

FRAME WORK AND PERCENTAGE MARKS DISTRIBUTION FOR PROPOSED PEDAGOGICAL METHOD

\begin{tabular}{|c|l|l|}
\hline S1.No & Frame work & $\%$ Marks distribution \\
\hline 1 & $\begin{array}{l}\text { Identification of sub blocks for the given problem } \\
\text { statement and algorithm }\end{array}$ & $10 \%$ \\
\hline 2 & $\begin{array}{l}\text { Program execution, Simulation results for sub blocks } \\
\text { Simulation result for Integration of various sub- } \\
\text { blocks }\end{array}$ & $20 \%$ \\
\hline 4 & PCB layout & $20 \%$ \\
\hline 5 & Hardware implementation & $20 \%$ \\
\hline 6 & Documentation & $20 \%$ \\
\hline
\end{tabular}

TABLE III

DESCRIPTION OF GRADUATE ATtRIBUTES CAN BE ATTAINED USING PROPOSED PEDAGOGICAL METHOD

\begin{tabular}{|c|l|l|l|}
\hline S1.No & Graduate Attributes & Competency & Indicators \\
\hline 1 & $\begin{array}{l}\text { PO1: Engineering knowledge: Apply the knowledge } \\
\text { of mathematics, science, engineering fundamentals, } \\
\text { and an engineering specialisation for the solution of } \\
\text { complex engineering problems. }\end{array}$ & $\begin{array}{l}1.4 \text { Demonstrate competence in } \\
\text { Electrical engineering knowledge }\end{array}$ & $\begin{array}{l}1.4 .1 \text { Apply discipline specific laws } \\
\text { and principles to solve an engineer- } \\
\text { ing problem. }\end{array}$ \\
\hline 2 & $\begin{array}{l}\text { PO3: Design/Development of Solutions: Design so- } \\
\text { lutions for complex engineering problems and de- } \\
\text { sign system components or processes that meet the } \\
\text { specified needs with appropriate consideration for } \\
\text { public health and safety, and cultural, societal, and } \\
\text { environmental considerations. }\end{array}$ & $\begin{array}{l}3.4 \text { Demonstrate an ability to ad- } \\
\text { vance an engineering design to de- } \\
\text { fined end state. }\end{array}$ & $\begin{array}{l}3.4 .1 \text { Refine a conceptual design } \\
\text { into a detailed design within the ex- } \\
\text { isting constraints (of the resources) }\end{array}$ \\
\hline
\end{tabular}




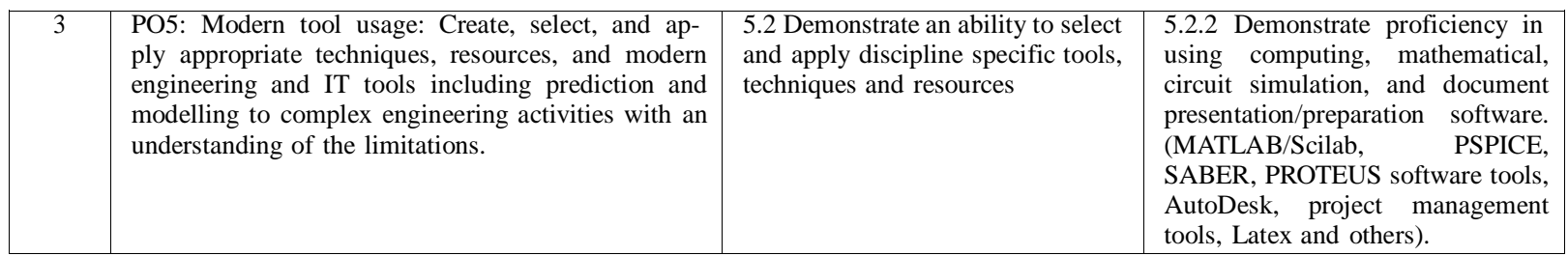

TABLE IV

FEASible PROGRAM OUTCOMES THAT CAN BE ATTAINED THROUGH PROPOSED METHOD

\begin{tabular}{|c|c|c|}
\hline S1.No & GA & Proposed method \\
\hline 1 & PO1 & High \\
\hline 2 & PO2 & Medium \\
\hline 3 & PO3 & Medium \\
\hline 4 & PO4 & Medium \\
\hline 5 & PO5 & High \\
\hline 6 & PO9 & High \\
\hline 7 & PO5 & High \\
\hline
\end{tabular}

